\title{
Some issues for the biosafety protocol
}

Sir - The letter from Crompton et al., describing themselves as "individuals involved in either the development or implementation of risk assessment frameworks for biotechnology" regulations mandated by the Convention on Biological Diversity (CBD) - illustrates perfectly the emerging problems of those efforts (Nature 391, 528; 1998).

The authors assert that biosafety regulations should involve "the overt consideration of socioeconomic issues before the environmental release or transboundary movement of genetically modified organisms" (defined narrowly as those crafted with molecular techniques of genetic manipulation). In other words, any field trial, anywhere, of a new, recombinant strain of Rhizobium or a new variety of transgenic maize would be subject to an evaluation of possible social and economic impact, anywhere else in the world.

The basic premise of the CBD-mandated biosafety protocol - that the most precise, molecular techniques of genetic

manipulation deserve extra scrutiny because they confer on products incremental risk is contrary to scientific consensus. As a leading article in Nature has said (356, 1-2; 1992), a broad scientific consensus holds that "the same physical and biological laws govern the response of organisms modified by modern molecular and cellular methods and those produced by classical methods .... [Therefore] no conceptual distinction exists between genetic modification of plants and microorganisms by classical methods or by molecular techniques that modify DNA and transfer genes." Triggers to government supervision should therefore focus on product traits that may be related to risk rather than on whether one or another technique of genetic manipulation was used.

Furthermore, a requirement to consider socioeconomic factors before the field testing of a recombinant organism would imply the following kinds of scenarios and mandatory assessments.

- Any pest- or disease-resistant plant: What would be the possible impact on workers, companies and countries manufacturing chemical pesticides?

- New plant varieties engineered to produce plastics or other substances now derived from petroleum: What would be the effects on the economies of the Persian Gulf states and other OPEC countries?

- A new malaria or schistosomiasis vaccine delivered in an edible fruit: How will national infrastructures absorb increases in population if the death rate from those highly prevalent diseases falls precipitously?

If such questions can ever be answered accurately, there is certainly little likelihood of doing so while products are at an early stage of testing. At any stage, such efforts would constitute major interdisciplinary research projects and would be highly vulnerable to the vagaries of value judgements. Moreover, such analyses have not been required for other technological innovations, from the internal combustion engine and electric automobiles to semidwarf wheat varieties and seedless grapes.

Finally, there is the more basic issue of whether a commitment to free trade and markets makes such requirements appropriate or useful at any time.

Henry I. Miller

Hoover Institution,

Stanford, California, USA

e-mail:miller@hoover.stanford.edu

Charles J. Arntzen

Boyce Thompson Institute,

Ithaca, New York, USA

Roger N. Beachy

Division of Plant Biology,

Scripps Research Institute, USA

\section{R. James Cook}

Department of Plant Pathology,

Washington State University, USA

Susanne L. Huttner

University of California,

Systemwide Biotechnology Program,

Berkeley, California, USA

Donald Kennedy

Institute for International Studies,

Stanford University, USA

\section{Calvin O. Qualset}

Genetic Resources Conservation Program, Division of Agriculture and Natural Resources,

University of California, USA

Peter H. Raven

Missouri Botanical Garden, and Washington University, USA

Anne K. Vidaver

Department of Plant Pathology,

University of Nebraska, USA

\section{A pawn in a conspiracy?}

Sir - Although I appreciate the legitimate bioethical concerns of emerging neurogenetic and neuroimaging technology, I do not believe the slope is quite as slippery as Jean-Pierre Changeux and Denis Le Bihan suggest (see Nature 391, $316 ; 1998)$. Neuroimaging hardly seems capable of "invasion of personal liberty, control of behaviour and brainwashing", and the assertion that neuroimaging can "almost read people's thoughts" is scientifically ridiculous and philosophically naive.

They paint a frightening picture of a post-apocalyptic Big Brother neuroscientist armed with pocket magnetic resonance imaging that works at a distance in real time on moving subjects engaged in Godknows-what cognitive and metabolic activity and meaningfully translates these signals into a universal language revealing the subjective thoughts of the individuals scanned, only then to control their minds and behaviour. Such broadcasting of thoughts and mind control sound like the results of schizophrenic processes rather than bioethical enquiries. Of course, I'm probably just a pawn in the conspiracy.

\section{George A. Mashour}

Georgetown University School of Medicine, 3970 Reservoir Road, RB-W225,

Washington, DC 20007, USA

\section{Early Alpine industry}

Sir - One of the 'great mysteries' of Ötzi, the Stone Age man whose body was found in an Alpine glacier (Nature 391, 318; 1997), was recently solved. A copper axe had been found close to the body, which was (as you indicated) dated as more than 5,000 years old. Copper tools were not yet known from such an early time in prehistory, so that some scientists believed that the body and the axe were found together only incidentally.
It was proved recently, however, that Ötzi lived not only contemporaneously with the axe, but also that he was probably involved in its manufacture. This was indicated by analysis of hair samples, which showed increased copper and arsenic content, comparable to concentrations found nowadays in the hair of people who work - under relatively primitive conditions - in the copper industry.

The Alpine region where Ötzi was found contains, indeed, some morphological remnants of pits where, apparently, copper ores were mined in prehistoric times. This makes the likelihood of a copper industry during Ötzi's lifetime almost certain. The finding of the 'Ice Man' thus sheds new light on the development of a metal industry in prehistoric times.

A. J. (Tom) van Loon

Geocom, PO Box 336,

NL-6860 AH Oosterbeek,

The Netherlands

e-mail:tom.van.loon@wxs.nl 